\title{
DATA ENVELOPMENT ANALYSIS IN IMPROVING SECURITY LEVEL IN LOCAL GOVERNMENT UNITS ${ }^{11^{*}}$
}

\author{
Jelena Jardas Antonić12
}

Received: February 28, 2018 / Revised: June 4, 2018 / Accepted: June 29, 2018

(C) Association of Economists and Managers of the Balkans, 2018

\begin{abstract}
Digital transformation and global trends in Smart City development have brought on serious security challenges in governing smart data assets. The implementation of two-way communication between cities and citizens requires secure communication channels and efficient data management. Fast development of information communication technologies (ICT) demands for continues investments in new security options. In this paper, the author examined the efficiency of implemented security levels in local government units (LGUs) through Data Envelopment Analysis. The Data Envelopment Analysis enables benchmarking LGUs according to obtained results. The efficient $L G$ units were further examined and were ranked using super-efficiency analysis. The inefficient LGUs can use the obtained results to improve their performance using projections and thus reach the efficiency frontier.
\end{abstract}

Keywords: Information security, LGU, Data Envelopment Analysis, super-efficiency

\section{JEL Classifications C61 $\cdot$ H79 $\cdot$ L86}

This paper was presented at the Second International Scientific Conference on Economics and Management - EMAN 2018, March 22 2018, Ljubljana, Slovenia, www.eman-conference.org

\footnotetext{
ఐ Jelena Jardas Antonić jjardas@gmail.com

* This paper has been financially supported by the University of Rijeka, for the project ZP UNIRI 10/17

12 University of Rijeka: Faculty of Economics, Ivana Filipovića 4, 51000 Rijeka, Croatia
} 


\section{INTRODUCTION}

Nowadays, no organization can survive unless it is ready to adopt changes brought by digital transformation. Having in mind that today's organizations completely rely on information and communication technologies that their survival depends on the use and a well-established implementation of these technologies. We can say that information security represents the next challenge. Information security has become an imperative because each organization uses, processes and stores, between other, confidential and business critical data. This challenge is also put in front of public institutions like hospitals, schools, high-educational institutions, as well as local government units (LGUs). That need to provide information and services, be open and transparent and on the same time provide security of its services and confidentiality of user's data. Implementing a safe and reliable infrastructure, is becoming more and more vital, so many authors addressing risk management often point out that information security is a crucial factor in eBusiness (Safa et al., 2015).

A successfully implemented ICT can reduce the costs and speed in the implementation of business processes, reduce human resources costs, and even be a key factor in competitive advantages. The implementation of ICT in public administration goes beyond the goals of commercial information systems due to the fact that it includes goals related to community wellbeing, political and social goals, etc. The positive effects of implementing and using ICTs in the public sector are reflected, according to Brown (2005), in four major areas: 1) As part of the services can be obtained 24/7 by the citizens themselves, bureaucratic procedures i.e. costs are decreased, 2) Information has become an equally valuable public resource, 3) The network infrastructure contributes to better connectivity, teamwork and collaboration within the organization itself and its environment and 4) ICT implementation brought on a shift in accountability and management models (empowerment of subordinates and accountability to citizens). All this reduces structural hierarchy and consequently leads to qualitatively different working conditions and working relationships. However, e- Government also has its drawbacks.

The shortcomings of e-government implementation in the Republic of Croatia are outlined in the Strategy E-Croatia 2020 (2015). The SWOT analysis shows that (p.42) apart from the lack of financial resources and organizational inadequacy, e- government faces the following threats: delays in execution and implementation, lack of high quality IT staff in public administration, the public fear regarding information security and personal data protection and the resistance to change i.e. to the transition from paper to electronic data processing.

Based on the reviewed literature, the Strategy for Electronic Administration 2009-2012 and the eStrategy 2015-2020, according to which one of the key determinants for a successful e-Government is successful ICT and information security implementation which should ensure reliable, continuous and safe service delivery. The goal of this paper is to examine the level of security of electronic business operations in local government units using Data Envelopment Analysis (DEA).

\section{METHODOLOGY}

\section{1. Data Envelopment Analysis}

Data Envelopment Analysis (DEA) is a data-oriented, non-parametric approach in the evaluation of the efficiency of a set of entities called decision-making units (DMU).

The CCR (Charnes, Cooper, Rhodes) and the BCC (Banker, Charnes, Cooper) model are two basic models that are frequently used in efficiency analyses. According to these models, for each 
decision-making unit (DMU) a virtual input, output and weights $v_{i}$ and $u_{r}$ are formed (Cooper, Seiford, Tone, 2006).

The desired common items of input and output are selected as follows (Cooper, Seiford, Tone, 2006):

- The numerical data should be available for each input and output, and should be positive for each DMU.

- The selected items (input, output and selected DMU) should reflect management (or the analyst's) interest in the components entering the evaluation of the relative efficiency.

- The items should be selected based on the principle of proportionality i.e. that a smaller amount of inputs and a larger quantity of output is preferable.

- The measurements units of various inputs and outputs need not be coincidental.

Let's assume that $\mathrm{m}$ inputs and s outputs with first two properties are selected, and that the input and output values are given as $\left(x_{1 j}, x_{2 j}, x_{3 j}, \ldots, x_{m j}\right)$ and $\left(y_{1 j}, y_{2 j}, y_{3 j}, \ldots, y_{s j}\right)$. The relative efficiency of each DMU is measured in line with the selected data, which means that it is necessary to solve $\mathrm{n}$ optimizations i.e. one for each DMU.

In the liner programming the problem form is given by:

$$
\begin{gathered}
\qquad \max _{\mu, v} \theta=\mu_{1} y_{1 o}+\mu_{2} y_{2 o}+\ldots+\mu_{s} y_{s o} \\
\text { with respect to } v_{1} x_{1 o}+v_{2} x_{2 o}+\ldots+v_{m} x_{m o}=1 \\
\mu_{1} y_{1 j}+\mu_{2} y_{2 j}+\ldots+\mu_{s} y_{s j} \leq v_{1} x_{1 j}+v_{2} x_{2 j}+\ldots+v_{m} x_{m j} \quad j=1, \ldots, n \\
\mu_{1}, \mu_{2}, \ldots, \mu_{s} \geq 0 \\
v_{1}, v_{2}, \ldots, v_{m} \geq 0
\end{gathered}
$$

Constraints ensure that the ratio of "virtual output" and "the virtual input" do not exceed 1 for each DMU. The goal is to gain weight values $\left(v_{i}\right)$ and $\left(u_{r}\right)$ to maximize the ratio of the evaluated unit. The optimum value that can be obtained for $\theta^{*}$ is 1 . We will assume that all inputs and outputs have a non-zero value, which will be reflected in the value of weights $v_{i}$ and $u_{r}$. These will be assigned positive values.

The CCR and BCC models differ in that the BCC model, in contrast to the CCR model, includes the condition of convexity $\sum_{j=1}^{n} \lambda_{j}=1, \lambda_{j} \geq 0, \forall j$ in constraints thus achieving that the frontier has piecewise linear and concave features as shown in Figure 1. Namely, the convexity condition leads to variable return to scale. 
Figure 1: Graphical presentations of the CCR and BCC models
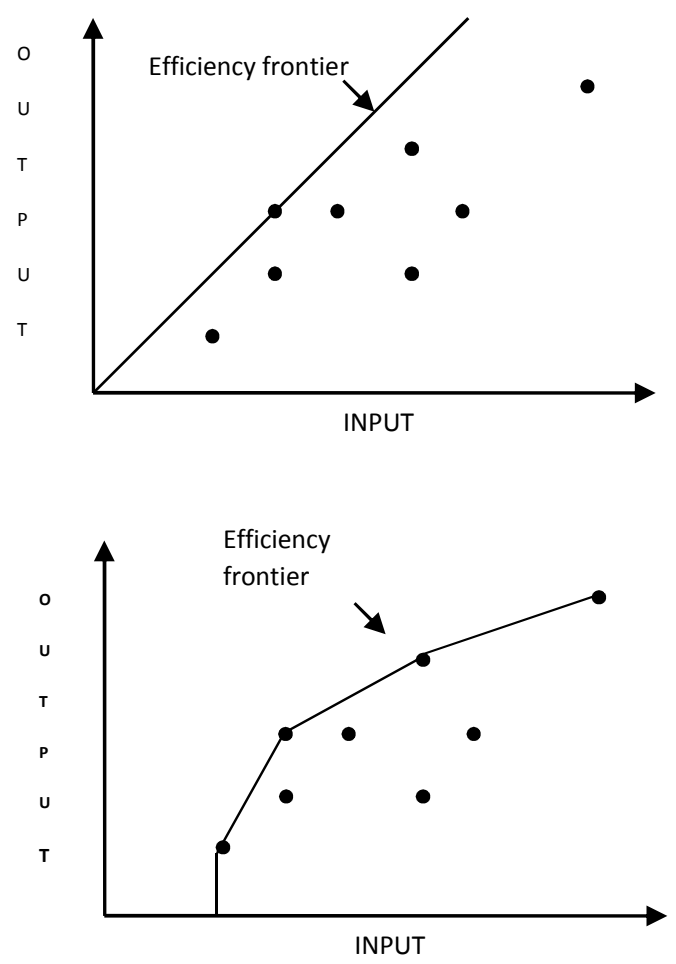

Source: Author's

After basic analysis using these two models, efficient units are evaluated using super efficiency model.

\subsection{Super efficiency model}

As previously stated, all efficient DMUs according to data envelopment analysis are ranked equally in terms of performance. Standard DEA models have a large number of applications and modification. One of the most important extensions of the DEA model is the formulation of superefficiency models used for ranking DMUs with an efficiency unity score. The most well- known super efficiency model is that established by Anderson and Petersen in 1993. This model involves executing standard DEA models (constant return to scale and variable return to scale) under the assumption that the evaluated DMUs are excluded from the reference set.

The super efficiency model is given by (Petersen, Anderson 1993):

subject to

$$
\min E_{j}-\delta e^{\prime} s^{-}-\delta e^{\prime} s^{+}
$$

$$
E_{j} X_{j}=\sum_{\substack{k=1 \\ k \neq j}}^{n} z_{k} X_{k}+s^{-}
$$




$$
Y_{j}=\sum_{\substack{k=1 \\ k \neq j}}^{n} z_{k} Y_{k}+s^{+}, \quad \mathrm{Z}, s^{+}, s^{-} \geq 0
$$

where $X_{j}$ represents the m-dimensional vector of input, $Y_{j}$ the s-dimensional output vector, $E_{j}$ the scalar which defines the share of the input vector for DMU necessary for producing the $Y_{j}$ DMU's output vector within the frames of referent technology, $\mathrm{Z}$ the vector of intensity where $z_{k}$ represents the intensity of the k-unit, $\delta$ the non-Archimedean infinitesimal, and $e^{\prime}$ the unity vector of appropriate dimension.

The consequence of excluding an evaluated unit taking from the reference set is easily understandable (see Figure 2). In the example there are five units marked with the letters from A to E. Each of the five units produces one output using two inputs. The stretch of the unity isoquant between given DMUs is presented in Figure 2.

Figure 2: Evaluating super-efficiency of DMU C

\section{Ratio $\mathrm{OC}^{1} / \mathrm{OC}$ define measure of efficiency in the evaluation unit $\mathrm{C}$ according to the model}

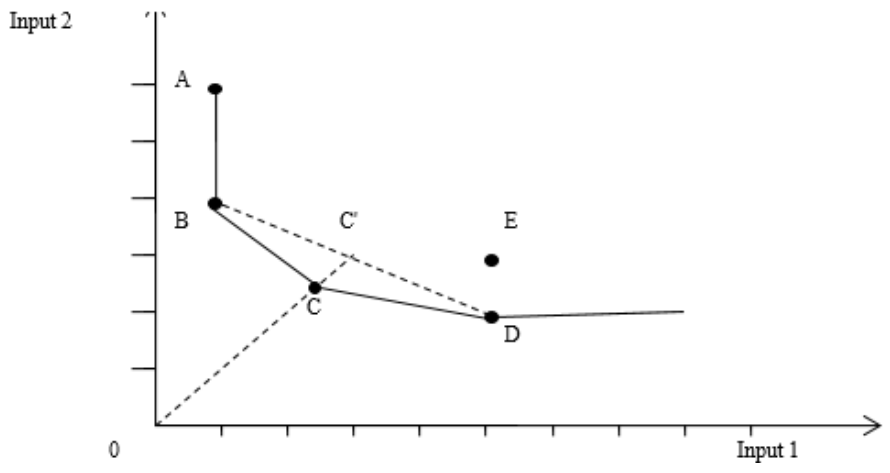

Source: Anderson, Petersen, 1993.

In Figure 2, the unity isoquant is stretched between <-BCD-> in which the efficient subset is represented by segments $\mathrm{BC}$ and $\mathrm{CD}$.

If we consider the evaluation of unit A, we can say that it is inefficient, as it needs 4 more units of input 2 than unit $B$ for the same input 1 . The elimination of inefficient observations will not affect the spreading set of referent units. It can be concluded that the super efficiency model and the BCC model show the same index of efficiency for unit (point) B.

If we consider the evaluation of unit $\mathrm{C}$, we can say that according to the $\mathrm{BCC}$ model, its index of efficiency equals 1 . By eliminating unit $C$ from the reference set, it is moved to a new unity isoquant stretching between the remaining elements from the set $(\mathrm{A}, \mathrm{B}, \mathrm{D}, \mathrm{E})$ at a minimal distance from its previous position. The reference point thus becomes $C^{\prime}(6.0,6.0)$ and unit $\mathrm{C}$ is assigned an efficiency index of 1.2 instead of 1 . 
The index of efficiency for the inefficient unit $\mathrm{E}$ in the new model will not change. The defined index of efficiency in the new model leads to the following ranking of units $\mathrm{A}-\mathrm{E}$ : $\mathrm{B}>\mathrm{D}>\mathrm{C}>\mathrm{A}$ $>$ E.

In their paper, Lovell and Rouse (2003) suggested many possible uses for super efficiency models including ranking of efficient DMUs, classification of DMUs into extreme-efficient and nonextreme efficient groups, sensitivity of efficiency classifications, two person ratio efficiency games, identifying outliers in the data, calculating and decomposing a Malmquist productivity index, overcoming truncation problems in second stages regressions intended to explain variation in efficiency.

In practice, the use of DEA efficiency and super-efficiency models is widespread, especially in non-profitable sectors. There are several examples of evaluating the efficiency of local government unit management using the Malmquist approach, as well as examples of using DEA for evaluating the maturity level of ICT in LGUs and the impact of economies of scale and uncontrollable factors on the relative efficiency of municipal service delivery. Du et al. (2014) explore the super efficiency of Pennsylvania hospitals; in their article University library benchmarking: An international comparison using DEA, Reichmann and Sommersguter-Reichmann propose a framework for assessing the technical efficiency and calculate the super efficiency of 118 university libraries from Australia, Austria, Canada, Germany, Switzerland and the United States (Reichmann, Sommersguter-Reichmann, 2006); Chodakowska uses DEA to evaluate lower secondary schools' management (2005) and Pavlić-Skender and Jardas Antonić (2015) use the BCC model to evaluate the efficiency of port management.

In this paper, the author uses the BCC and the super-efficiency models to evaluate the information security level in local government units (LGUs). Namely, information security has become a topical issue because in addition to the advantages of digitalization i.e. the transparency and availability of public services, there is an increasing demand for protection personal data (Miszczyński, 2013; Mamoon, 2012).

\section{DATA AND ANALYSIS}

The information systems of local government units (LGU) are analyzed based on five areas important for the functioning of e-Government. The data for the analysis of the efficiency of 41 local government unis was gathered through a questionnaire developed by the author and sent out to the respective LGUs. The segments used in this research included data on the number of IT staff, maturity level of IT management, number of servers in LGUs, application and documentation coverage, and on implemented information security controls. Figure 3 presents the level of implementation of individual information security controls in Croatian LGUs. 
Figure 3. Security controls in Croatian local government units

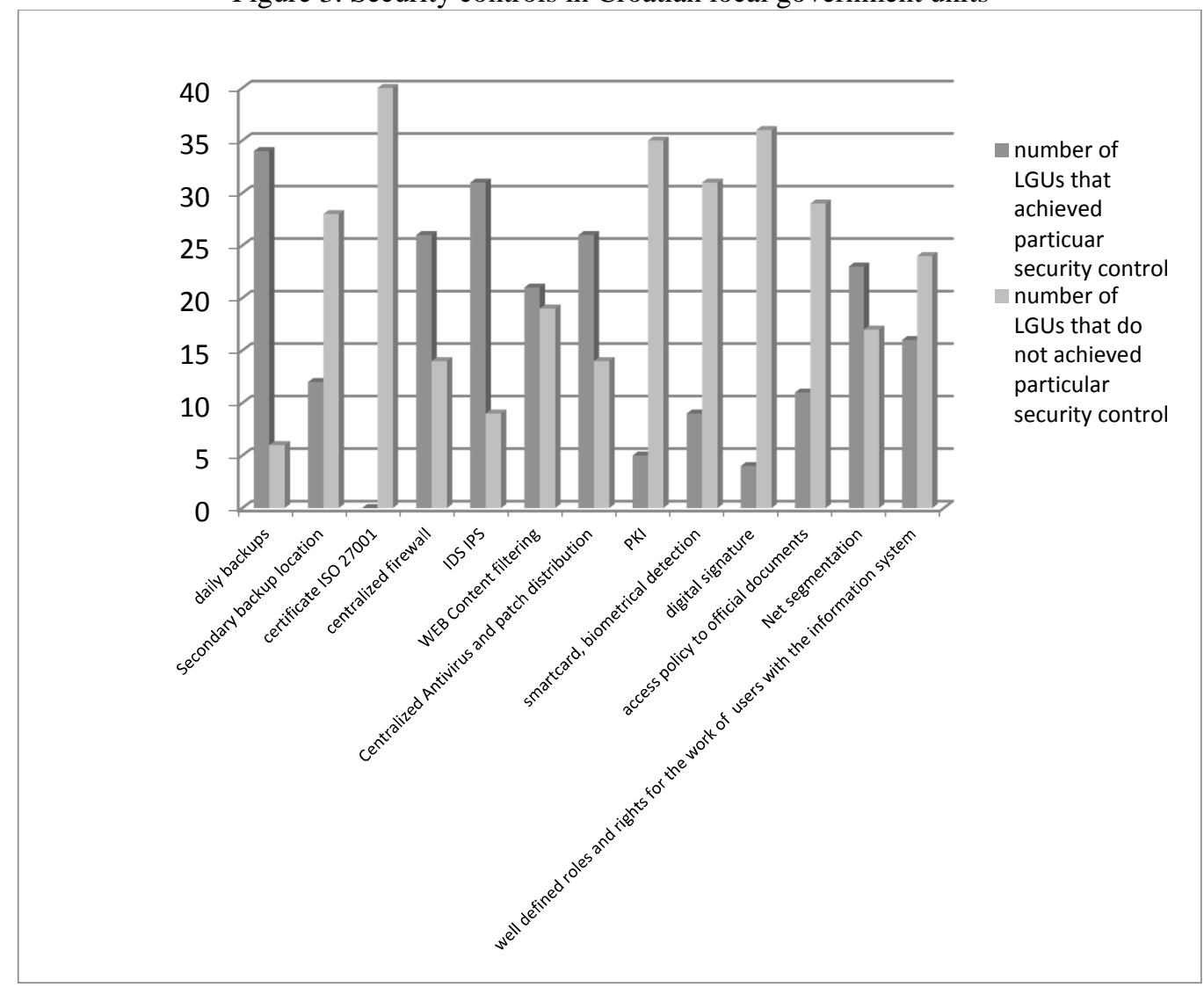

Source: Author

As we can see, daily backups are conducted in $85 \%$ of cities and IDS/IPS (Intrusion Prevention System/Intrusion Detection System) in $78 \%$ of them. However, the usage of all other control system is very concerning.

In order to analyze the efficiency level of information security, the above-presented security control have been aggregated to obtain an output. The number of selected items is limited by the number of LGUs. The number of units should be at least 3 times larger than the sum of selected inputs and outputs. In our analysis, four inputs and one output is selected.

Table 1. Table of selected inputs and output

\begin{tabular}{|l|l|}
\hline Variables & Description \\
\hline Inputs & Number of staff in IT department \\
\hline NoITstaff & Maturity level of IT management \\
\hline CobIT Est & Number of servers in LGU \\
\hline No.servers & $\begin{array}{l}\text { Coverage with specific applications } \\
+ \text { documentation coverage }\end{array}$ \\
\hline Aplic-doc & Information security level \\
\hline Output & Author \\
\hline InfSec
\end{tabular}

Source: Author 
According to the table, the number of IT staff, maturity level of IT management, the number of servers in each LGU and specific application and documentation coverage are taken as inputs and security as the output in the analysis. The security output was obtained by assessing whether a certain city administration has implemented an Information Security Management System certified according to the International Standard such as ISO 27001, whether the users roles and rights within the information system are precisely defined, whether it has implemented smart card authentication, whether it has web content filtering, etc.

Table 2. Summary results of BCC and CCR output oriented models

\begin{tabular}{|l|c|c|}
\hline & CCR & BCC \\
\hline No. of DMU taken into analysis & 41 & 41 \\
\hline No. of relatively efficient & 6 & 16 \\
& $(14.6 \%)$ & $(39 \%)$ \\
\hline Avr. relative efficiency & 0.7515 & 0.8434 \\
\hline Maximum & 1 & 1 \\
\hline Minimum & 0.2436 & 0.4 \\
\hline No. of DMUs with relative efficiency below the average & 20 & 16 \\
\hline
\end{tabular}

Source: Author's calculation

After selecting the inputs and the output, we conduct Data Envelopment Analysis using two basic models. The BCC model was selected as preferable because the output does not change proportionally with the increase in inputs. According to the literature, the variable return to scale is taken as the preferable model if the difference between efficient DMUs in the BCC and the CCR model is significant. In our case that difference is approximately $24 \%$.

Aggregate results show (Table 2) that the average DMU efficiency obtained by CCR is 0.84349 which means that if an average DMU wants to move on the efficiency frontier, it has to increase the output for $18.56 \%$ at the same level of inputs. There are $39 \%$ of relatively efficient units according to the BCC model and $14.6 \%$ according to the CCR model. The average efficiency levels are high and amount to $75.15 \%$ according to CCR, and $84.3 \%$ according to the BCC model.

Table 3. Scores and ranks for 41 local government units

\begin{tabular}{|c|c|c|c|c|c|}
\hline DMU & Score & Rank & DMU & Score & Rank \\
\hline $\operatorname{lgu} 3$ & 1 & 1 & $\operatorname{lgu} 33$ & 0.915 & 21 \\
\hline $\operatorname{lgu} 4$ & 1 & 1 & $\operatorname{lgu} 38$ & 0.9057 & 22 \\
\hline $\operatorname{lgu} 5$ & 1 & 1 & $\operatorname{lgu} 1$ & 0.8889 & 23 \\
\hline $\operatorname{lgu} 8$ & 1 & 1 & $\operatorname{lgu} 15$ & 0.8873 & 24 \\
\hline $\operatorname{lgu} 9$ & 1 & 1 & $\operatorname{lgu} 21$ & 0.8485 & 25 \\
\hline $\operatorname{lgu} 11$ & 1 & 1 & $\operatorname{lgu} 19$ & 0.8333 & 26 \\
\hline $\operatorname{lgu} 17$ & 1 & 1 & $\operatorname{lgu} 16$ & 0.7914 & 27 \\
\hline $\operatorname{lgu} 22$ & 1 & 1 & $\operatorname{lgu} 7$ & 0.7778 & 28 \\
\hline $\operatorname{lgu} 23$ & 1 & 1 & $\operatorname{lgu} 39$ & 0.7752 & 29 \\
\hline $\operatorname{lgu} 25$ & 1 & 1 & $\operatorname{lgu} 27$ & 0.7714 & 30 \\
\hline $\operatorname{lgu} 26$ & 1 & 1 & $\operatorname{lgu} 36$ & 0.7547 & 31 \\
\hline $\operatorname{lgu} 30$ & 1 & 1 & $\operatorname{lgu} 6$ & 0.7059 & 32 \\
\hline $\operatorname{lgu} 32$ & 1 & 1 & $\operatorname{lgu} 12$ & 0.6667 & 33 \\
\hline $\operatorname{lgu} 34$ & 1 & 1 & $\operatorname{lgu} 20$ & 0.6667 & 33 \\
\hline $\operatorname{lgu} 35$ & 1 & 1 & $\operatorname{lgu} 31$ & 0.6349 & 35 \\
\hline $\operatorname{lgu} 41$ & 1 & 1 & $\operatorname{lgu} 18$ & 0.5714 & 36 \\
\hline
\end{tabular}




\begin{tabular}{|l|l|l|c|c|c|}
$\operatorname{lgu} 2$ & 0.9999 & 17 & $\operatorname{lgu} 28$ & 0.5333 & 37 \\
\hline $\operatorname{lgu} 37$ & 0.9677 & 18 & $\operatorname{lgu} 29$ & 0.5 & 38 \\
\hline $\operatorname{lgu} 24$ & 0.9474 & 19 & $\operatorname{lgu} 10$ & 0.4444 & 39 \\
\hline $\operatorname{lgu} 40$ & 0.9474 & 19 & $\operatorname{lgu} 14$ & 0.4444 & 39 \\
\cline { 4 - 6 } & & $\operatorname{lgu} 13$ & 0.4 & 41 \\
\hline
\end{tabular}

Source: Author's calculations

As can be seen from Table 3, almost all big city local government units in the Republic of Croatia reach the efficiency frontier, as well as those who are geographically positioned very close to them as their closeness to big cities probably affects their awareness of the importance of information security. Moreover, Application and documentation coverage has shown to be the mostly correlated input with the security output, which might indicate that, those cities who have a wellestablished documentation base, have also better defined security procedures and roles according to Information Security Management System standards.

The next step is to calculate projections for each inefficient DMU i.e. the see how they can reach higher security levels with unchanged (or with minor changes) in inputs by using the reference set and by benchmarking the inefficient units with those units that have higher levels of efficiency i.e. security with similar inputs.

Table 4. Projections and reference set for an inefficient DMU

\begin{tabular}{|c|c|c|c|c|c|}
\hline DMU & Score & Rank & Output Data & Projection & Diff.(\%) \\
\hline $\lg u 36$ & 0.7547 & 31 & 6 & 7.95003 & 32.501 \\
\hline DMU & Score & Rank & \multicolumn{3}{|c|}{ Reference(Lambda) } \\
\hline $\operatorname{lgu} 36$ & 0.7547 & 31 & $\operatorname{lgu} 9$ & $\lg 23$ & lgu 26 \\
\hline
\end{tabular}

Source: Author's calculation

In Table 4 gives an example of projections and reference set for the LGU 36. This unit can reach the relative efficiency frontier if it improves its security level for $32.5 \%$ with minimum or no changes in inputs. The reference set for LGU 36 includes three LGUs with similar or lower values of inputs but with higher or same security level output. These three units represent role models for improving its performance.

Data Envelopment Analysis represents a valuable tool for benchmarking between homogeneous units that operate under similar conditions. Local government units fall into this category which allows for inefficient units to use projections and improve their performance. As the standard BCC and CCR models do not rank efficient units, this is done by using the super-BCC model.

Table 5. Efficiency ranking of efficient units according to the Super-BCC and the BCC models

\begin{tabular}{|c|c|c|c|c|c|}
\hline Rank & DMU & $\begin{array}{c}\text { Score (Super } \\
\text { BBC) }\end{array}$ & Rank & DMU & $\begin{array}{c}\text { Score } \\
\text { (BCC) }\end{array}$ \\
\hline 1 & $\operatorname{lgu} 23$ & 2.999925 & 1 & $\operatorname{lgu} 3$ & 1 \\
\hline 2 & $\operatorname{lgu} 5$ & 1.9999 & 1 & $\operatorname{lgu} 4$ & 1 \\
\hline 3 & $\operatorname{lgu} 9$ & 1.499993 & 1 & $\operatorname{lgu} 5$ & 1 \\
\hline 4 & $\operatorname{lgu} 4$ & 1.499982 & 1 & $\operatorname{lgu} 8$ & 1 \\
\hline 5 & $\operatorname{lgu} 8$ & 1.4 & 1 & $\operatorname{lgu} 9$ & 1 \\
\hline 6 & $\operatorname{lgu} 26$ & 1.185366 & 1 & $\operatorname{lgu} 11$ & 1 \\
\hline 7 & $\operatorname{lgu} 11$ & 1.142857 & 1 & $\operatorname{lgu} 17$ & 1 \\
\hline 8 & $\operatorname{lgu} 34$ & 1.111969 & 1 & $\operatorname{lgu} 22$ & 1 \\
\hline
\end{tabular}




\begin{tabular}{|c|c|c|c|c|c|}
\hline 9 & $\operatorname{lgu} 3$ & 1.090908 & 1 & $\operatorname{lgu} 23$ & 1 \\
\hline 10 & $\operatorname{lgu} 22$ & 1.076923 & 1 & $\operatorname{lgu} 25$ & 1 \\
\hline 11 & $\operatorname{lgu} 41$ & 1.067157 & 1 & $\operatorname{lgu} 26$ & 1 \\
\hline 12 & $\operatorname{lgu} 30$ & 1.022727 & 1 & $\operatorname{lgu} 30$ & 1 \\
\hline 13 & $\operatorname{lgu} 2$ & 1 & 1 & $\operatorname{lgu} 32$ & 1 \\
\hline 13 & $\operatorname{lgu} 32$ & 1 & 1 & $\operatorname{lgu} 34$ & 1 \\
\hline 13 & $\operatorname{lgu} 17$ & 1 & 1 & $\operatorname{lgu} 35$ & 1 \\
\hline 13 & $\operatorname{lgu} 25$ & 1 & 1 & $\operatorname{lgu} 41$ & 1 \\
\hline
\end{tabular}

Source: Author's calculation

The super-BCC model ranks efficient units while inefficient units retain the same levels of efficiency estimation. Moreover, the advantage of the super-BCC model is that it allows those units which have been estimated as efficient by the standard BCC to get their own reference set which could help them to improve their efficiency score. However, as we can see from the results, four of the units retained the same efficiency score in both models, as they have no possibility for improvement.

\section{CONCLUSION}

Modern e-Government puts the citizens in the focus of its business processes and provides maximal availability of e-Services 24/7/365 and at the same time enables high level of reliability and data security. However, technological developments are always accompanied by threats and possibilities of abuse, which pose a huge challenge in e-Business security.

The approach described in this paper can serve local government units in their risk management and decision making processes and help them increase the relative efficiency of their security levels. In addition to this, it can serve as model for testing the efficiency of security levels in institutions such as banks, insurance companies, hospitals, where the security levels of e-Business is of great importance as in these institutions every minor negligence in the safety of their system can cause damages of large proportion in both financial and operational sense.

The obtained results show that $39 \%$ of LGUs are relatively efficient according to the BCC model whereas only $14.6 \%$ according to the CCR model. The average relative efficiency levels are high and amount to $75.15 \%$ according to CCR, and $84.3 \%$ according to BCC. However, we should point out that this paper analyses relative and not absolute efficiency. Moreover, Data Envelopment Analysis has proven to be a good tool for benchmarking homogeneous local government units. The strongest feature of DEA is that it provides for projections which can be used as guidelines by inefficient or less efficient LGUS in their improvement, in our case, in increased information security levels.

In the future, this research could be extended to include local government units from developed EU member states as this would provide new projections due to possible changes in the reference set. In addition to this, further research could focus on other possibilities provided by DEA, such as the possibility to divide local government units into separate categories according to their size or the number of available services. Another direction could be to restrict input (output) weights that are of less importance in assessing security levels i.e. by placing constraints on the weights which might provide for more realistic results. The third possibility could be to use DEA's window analysis to see and analyze the trends in security improvements or the lack of the same through longer periods of time. 


\section{REFERENCES}

Andersen, P., Petersen, N.C. (1993). A Procedure for Ranking Efficient Units in Data Envelopment Analysis, Management Science, 39(10), 1261 - 1264.

Brown, D. (2005). Electronic government and public administration, International Review of Administrative Sciences, 71(2), 241-254.

Chodakowska, E. (2015). The Future Of Evaluation Of Lower Secondary Schools' Management, Business, Management and education, 13(1), 112-125.

Cooper, W., Seiford, L., Tone K. (2006). Introduction to Data Envelopment Analysis and Its Uses, Springer.

$\mathrm{Du}$, J. et al (2014). Incorporating health outcomes in Pennsylvania hospital efficiency: an additive super-efficiency DEA approach, Annals of Operational Research, 221(1), 161-172.

Jardas Antonić, J.; Pavlić Skender, H. (2015). Efficiency of Passenger Seaports as a Factor in Tourism Development, 2nd International Multidiscliplinary Scientific Conference on Social Sciences \& Arts SGEM 2015. Book 2, Vol.3, 235-244.

Lovell, C., Rouse, A. (2003). Equivalent standard DEA models to provide super-efficiency scores, Journal of the Operational Research Society, 54(1), 101-108.

Mamoon, A., (2012) Assessing the Impact of Economies of Scale and Uncontrollable Factors on the Performance of U.S. Cities, doctoral dissertation, College of Health and Public Affairs, Orlando, Florida.

Miszczyński, P. M. (2013). Measuring the Efficiency of Local Government Units Management in the Central Region of Poland in a Dynamic Perspective, Quantitative Methods in Economics, 14(2), 108-117.

Reichmann, G., Sommersguter-Reichmann M. (2006). University library benchmarking: An international comparison using DEA, International Journal of Production Economics, 100(1), 131-147.

Safa, N. S. et al. (2015). Information security conscious care behavior formation in organizations, Computers \& Security, 53, 65-78.

Strategija E-Hrvatska (2015). Ministarstvo uprave RH. https://uprava.gov.hr/strategija-e-hrvatska$2020 / 14630$ 